\title{
Characterization of Brown Adipose-Like Tissue in Trauma-Induced Heterotopic Ossification in Humans
}

\author{
Elizabeth A. Salisbury, ${ }^{*}$ Austin R. Dickerson, ${ }^{*}$ Thomas A. Davis, ${ }^{\dagger \dagger}$ Jonathan A. Forsberg, ${ }^{\dagger \dagger}$ Alan R. Davis, ${ }^{*} \delta$ and \\ Elizabeth A. Olmsted-Davis ${ }^{\star \S \uparrow}$
}

\begin{abstract}
From the Center for Cell and Gene Therapy* and the Departments of Pediatrics ${ }^{\S}$ and Orthopedic Surgery, ${ }^{\S}$ Baylor College of Medicine, Houston, Texas; the Regenerative Medicine Department, ${ }^{\dagger}$ Naval Medical Research Center, Silver Spring, Maryland; and the Department of Orthopaedics, ${ }^{\ddagger}$ Uniform Services University-Walter Reed Department of Surgery, Walter Reed National Medical Center, Bethesda, Maryland
\end{abstract}

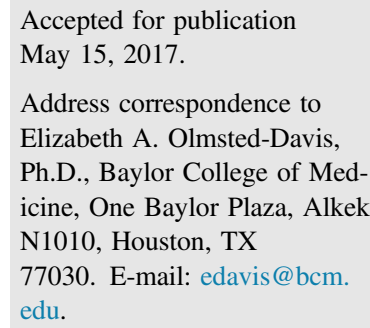

Heterotopic ossification ( $\mathrm{HO})$ is the ectopic formation of bone in soft tissues. HO most frequently occurs after traumatic injury to the brain and spinal cord, ${ }^{1}$ burns, ${ }^{2}$ fractures, ${ }^{3}$ and blasts. ${ }^{4,5}$ Within the military, the prevalence of HO has been shown to be $64 \%$ in soldiers experiencing severe combatrelated injuries. ${ }^{6}$ In some instances, this ectopic bone formation can surround nerves and vessels, resulting in their dysfunction. ${ }^{7}$ This can occur in addition to ulcerations, pain, and limited joint motion, which are more common complications of HO. Currently, the primary means of treatment for persistently symptomatic HO involves surgical excision of the bony lesion. ${ }^{8}$ The removal of these lesions can be problematic, requiring precise excision as well as wound complications. Furthermore, in certain cases, the lesions can reoccur. Therefore, the ability to detect and/or potentially block the progression of $\mathrm{HO}$ during its earliest stages would greatly improve efforts to prevent and treat this aberrant process.
Our previous studies, using a mouse model where HO is induced by bone morphogenetic protein 2 , found transient brown adipocytes drive the earliest steps of $\mathrm{HO}$ by generating a microenvironment conducive to bone formation. ${ }^{9-11}$ These cells are defined by their expression of uncoupling protein 1 (UCP1). UCP1 reduces the concentration of oxygen in the microenvironment, whereas the standard ATPase does not, because UCP1 has a much higher catalytic activity (nmole O $\min ^{-1} \mathrm{mg}$ mitochondrial protein ${ }^{-1}$ ) at a given membrane potential. ${ }^{12}$ It is this higher activity coupled with its ability to

Supported by the Department of Defense grant W81XWH-12-1-0274, NIH-National Institute of Arthritis and Musculoskeletal and Skin Diseases grant R21AR063779US, and NIH-National Institute of General Medical Sciences grant K12 GM084897.

Disclosures: None declared.

Current address of E.A.S., Department of Orthopaedic Surgery and Rehabilitation, University of Texas Medical Branch, Galveston, TX. 
generate heat, because oxygen solubility decreases as temperature increases, that causes UCP1 to function as a generator of a hypoxic microenvironment. It is one of the few proteins that can generate hypoxia, and we have previously shown that it can effectively accomplish this. ${ }^{9}$ Characterization of this transient brown adipose tissue (tBAT) induced during $\mathrm{HO}$ in mice revealed its cells selectively express many of the factors previously implicated in classic brown adipocyte development and function, such as the transcriptional regulator peroxisome proliferator-activated receptor $\gamma$ coactivator $1 \alpha .{ }^{9,11}$ However, these cells differ from classic brown adipocytes found in dedicated depots in that they do not express PRDM16, ${ }^{11}$ which has been shown to regulate the differentiation of myoblastic precursors into brown adipose tissue (BAT). ${ }^{13}$ These studies, therefore, suggest a specialized pool of brown adipocyte-like cells that contribute to HO.

In our mouse model of $\mathrm{HO}$, we found that the presence of tBAT coincides with the presence of hypoxia and the ultimate deposition of cartilage. ${ }^{9}$ The tBAT forms a region that is flanked on one side by cartilage (hypoxia) and on the other side by vessel formation (normoxia). ${ }^{9,11}$ This vessel formation is stimulated by the secretion of angiogenic factors from tBAT. ${ }^{10}$ Therefore, tBAT is involved in the patterning of bone and cartilage and is more than a simple generator of heat.

In recent years, the presence of BAT within adult humans has been found to be more widespread than originally thought. ${ }^{14-18}$ Depots of $\mathrm{UCP}^{+}$brown fat have been identified in specific regions throughout the body (supraclavicular, cervical, perirenal). ${ }^{15,16,19,20}$ Furthermore, cells with a brown fat-like phenotype that express UCP1, referred to as brite or beige adipocytes, can be induced within white fat depots. ${ }^{21,22}$ In rodents, this has been shown to occur on exposure to cold or $\beta 3$-adrenergic stimulation. Sidossis and Kajimura $^{23}$ recently confirmed the emergence of $\mathrm{UCP}^{+}$ brown fat-like cells within subcutaneous white fat after the prolonged adrenergic stress experienced by burn patients. ${ }^{24}$ Interestingly, brown adipocytes associated with $\mathrm{HO}$ in mice have been shown to express the $\beta 3$-adrenergic receptor (ADRB3) and to proliferate in response to noradrenaline. ${ }^{11}$ Because HO is often associated with severe burns, these cell populations may be similar.

Given the critical role identified for brown adipocyte-like cells in patterning $\mathrm{HO}$ in mice, ${ }^{9}$ as well as their emerging role in tissue regeneration, as evidenced by the extreme osteoporotic phenotype of mice lacking a key component in the formation of $\mathrm{tBAT},{ }^{25}$ we sought to determine if a similar cell could be found within human HO tissues.

\section{Materials and Methods}

\section{Tissue Sample Collection}

Human tissues were obtained during surgical removal of symptomatic lesions from 24 different patients experiencing a combat-related trauma to the extremities at Walter Reed National Military Medical Center, through an approved
Walter Reed Medical Center institutional review board protocol (number 374863). All human tissue transfers to Baylor College of Medicine (E.A.O.-D.) under an approved institutional review board protocol (H-30833) from Walter Reed National Military Medical Center (J.A.F.) followed the approved Cooperative Research and Development Agreement (NCRADA-NMRC-13-9127) between Baylor College of Medicine and the Department of the Navy.

These samples were classified as either early, preradiographic HO with palpable evidence of mineralization $(n=20)$ or mature $\mathrm{HO}$ with radiographically apparent ectopic bone formation $(n=4)$. Other properties of the patient population have been described previously. ${ }^{26,27}$ Control samples were obtained from discarded tissue collected from extremity-injured patients during an initial wound debridement procedure, before final wound closure. Subsequent follow-up of these patients confirmed none of them developed radiographic evidence of $\mathrm{HO}$. All collected tissues were fixed in $10 \%$ neutral-buffered formalin for histological analysis.

\section{Histological Assessment}

Tissues were fixed and transferred in $10 \%$ neutral-buffered formalin, decalcified in Richard-Allan Scientific Cal-Rite Decalcifying Solution (ThermoScientific, Kalamazoo, MI), trimmed for mounting in cassettes, and then processed and paraffin embedded. Serial sections $(5 \mu \mathrm{m}$ thick) were prepared, and every 10th section throughout the tissue sample was stained with hematoxylin and eosin for histological analysis. The tissue sections were examined by two authors (E.A.S. and A.R.D.), who were blinded to the tissue collection and radiographic results, for the following histological features: bone, fibroproliferation, blood vessels, nerve, cartilage, mature muscle, and adipose tissue (both white and brown adipocytes).

Bone was characterized by an eosinophilic matrix deposition, which was often accompanied by osteoblasts, osteoclasts, or osteocytes. Fibroproliferative lesions were identified as areas of accumulated fibroblastic cells rich with collagen fibers and other matrix components. Blood vessels were defined as thin vascular spaces, and nerves were identified by their characteristic arrangement of nerve fibers. Cartilage was classified by chondrocytes surrounded by a lacunar space and abundant matrix. Adipose tissue was identified as cells with globules of lipid-like material filling the cytoplasm. White fat is distinguished as a single large globule with a thin ring of cytoplasm and eccentric nuclei, whereas brown fat is differentiated by its multiple lipid droplets and abundant mitochondria, giving the appearance of a darker cell with a soap-bubble cytoplasm.

\section{Immunohistochemical Analysis}

Serial unstained slides, adjacent to hematoxylin and eosin-stained sections, were used for immunohistochemical staining (either single- or double-antibody labeling), using 
Table 1 Histological Assessment of Heterotopic Ossification Tissue Samples

\begin{tabular}{lc}
\hline Histological feature & Presence, $n(\%)$ \\
\hline Bone & $22(92)$ \\
Fibroproliferative lesion & $17(71)$ \\
Cartilage & $5(21)$ \\
Nerve & $3(12.5)$ \\
Blood vessels & $13(54)$ \\
White/brown adipocytes & $18(75)$ \\
Mature muscle & $16(67)$ \\
\hline
\end{tabular}

$n=24$ samples.

methods outlined previously. ${ }^{9}$ For double-antibody labeling, samples were treated with both primary antibodies simultaneously, followed by washing and incubation with respective secondary antibodies, used at a 1:500 dilution, to which Alexa Fluor 488 or 594 was conjugated. Primary antibodies were used as follows: UCP1, rabbit polyclonal, used at 1:100 dilution (EMD Millipore, Billerica, MA); peroxisome proliferator-activated receptor $\gamma$ coactivator $1 \alpha$, goat polyclonal, used at 1:100 dilution (LifeSpan Biosciences, Seattle, WA); PRDM16, rabbit polyclonal, used at 1:100 dilution (Abcam, Cambridge, MA); T-Box 1, rabbit polyclonal, used at a 1:100 dilution (Abcam); CD137, mouse monoclonal, used at a 1:100 dilution, (Abcam); peroxisome proliferatoractivated receptor $\gamma$, rabbit polyclonal, used at 1:200 dilution (Abcam); Homeobox C9, mouse monoclonal, used at 1:100 dilution (Abcam); Sry-Box 9, rabbit polyclonal, used at 1:100 dilution (Santa Cruz Biotechnology, Santa Cruz, CA); aggrecan, goat polyclonal, used at 1:20 dilution (R\&D Systems, Minneapolis, MN); neurofilament, mouse monoclonal, used at 1:200 dilution (Sigma-Aldrich, St. Louis, MO); and a mouse polyclonal antibody to the human ADRB3, used at 1:100 dilution (Abnova, Taipei City, Taiwan). Primary antibodies were diluted in either $2 \%$ bovine serum albumin or phosphate-buffered saline and $10 \%$ serum of the species in which the secondary antibody was generated. Tissues were mounted and counterstained using Vectashield mounting medium containing DAPI (Vector Laboratories, Burlingame, CA). Stained tissue sections were examined using an Olympus BX41 microscope (Olympus Corporation of the Americas, Waltham, MA) equipped with a reflected fluorescence system, using a $10 \times / 0.40$ numerical aperture, $20 \times /$ 0.75 numerical aperture, or $40 \times / 0.85$ numerical aperture objective lens.

\section{Results}

\section{Histological Characterization of Tissue}

A total of $24 \mathrm{HO}$ tissue samples were analyzed for specific histological features (Table 1). Figure 1 shows representative tissue sections stained with hematoxylin and eosin. Bone was histologically apparent in $22(92 \%)$ of the samples, consisting of both immature (Figure 1A) and mature (Figure 1B) bone areas. The immature $\mathrm{HO}$ tissue contained numerous osteoblasts lining the bone surface and multinucleated osteoclasts, suggesting active bone remodeling. Mature HO tissue, on the other hand, was characterized by a more lamellar arrangement of the bone matrix. We observed fibroproliferation, which has been reported in other forms of $\mathrm{HO},{ }^{28}$ in 17 (71\%) (Figure 1C) and cartilage formation in $5(21 \%)$ (Figure 1D) of the tissue specimens. Surrounding muscle tissue was noted in $16(67 \%)$ of the $\mathrm{HO}$ tissues (Figure $1 \mathrm{H})$. We also observed nerves and blood vessels in $3(12.5 \%)$ and $13(54 \%)$ of the tissue samples of HO, respectively (Figure 1, $\mathrm{E}$ and $\mathrm{F}$ ). Finally, we found adipose tissue, with regions of histology typical of both white and brown fat, in $75 \%$ of the tissues analyzed (Figure 1G).

\section{Expression of UCP1 within H0 Tissue Samples}

Brown adipocyte-like cells have been shown to be a central regulator of $\mathrm{HO}$ in mouse models because hypoxic regions produced by these cells are essential for chondrogenesis., 911

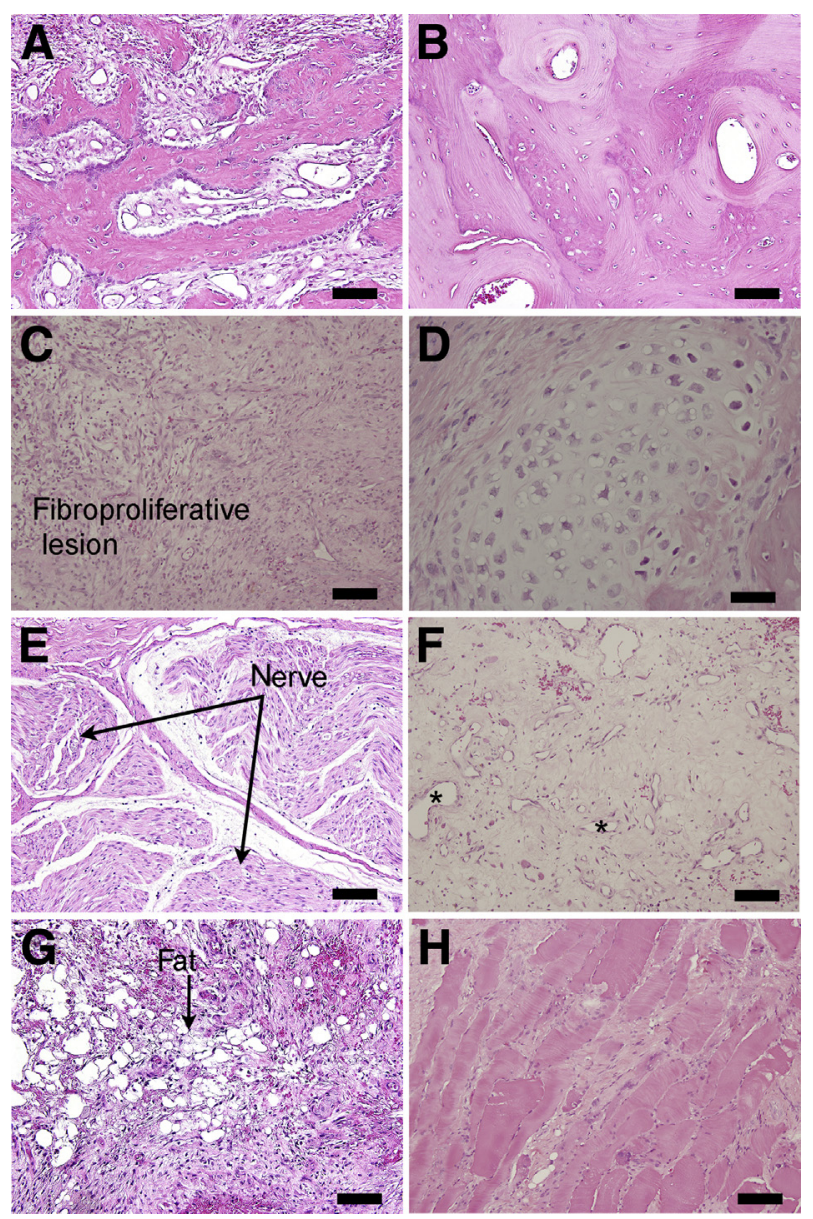

Figure 1 Histological assessment of $\mathrm{HO}$ tissue. Representative images of tissue sections from $\mathrm{HO}$ samples stained with hematoxylin and eosin. Photomicrographs of histological features identified within collected $\mathrm{HO}$ tissues, including immature (A) and mature (B) bone, fibroproliferative tissue (C), cartilage (D), nerves (E), blood vessels (asterisks; F), adipose tissue $(\mathbf{G})$, and the surrounding muscle fibers $(\mathbf{H})$. Scale bars: $100 \mu \mathrm{m}$ (A-C and $\mathbf{E}-\mathbf{H}) ; 50 \mu \mathrm{m}$ (D). 
Furthermore, adjoining regions characterized by vessel formation, which brown adipocyte-like cells also regulate, ${ }^{10,11}$ serve as osteoprogenitor entry points via extravasation. ${ }^{29}$ We assessed expression of the brown adipocyte-specific marker UCP1 within the tissue samples of human HO by immunohistochemistry. Figure 2 contains representative images of the UCP1 expression observed within different tissue samples. Hematoxylin and eosin staining was used. UCP1 $1^{+}$ cells were found within regions of adipose tissue adjacent to bone (Figure 2), muscle fibers (Figure 2), and vessels (Figure 2 ). $\mathrm{UCP}^{+}$cells were found within approximately $63 \%$ (15 of 24) of the human HO tissues analyzed. There was no detectable UCP1 expression in control tissues from patients who did not develop HO (Figure 3).

\section{UCP1 ${ }^{+}$Adipocytes in HO Tissues Express the Key} Transcription Factor Peroxisome Proliferator-Activated Receptor $\gamma$ Coactivator $1 \alpha$, but Not PDRM16 or Markers of Beige Fat Cells

To further characterize the $\mathrm{UCP} 1^{+}$adipocytes observed in the HO tissues, we immunostained for markers reported to be present in brown and beige adipocytes. ${ }^{21}$ Regions of adipocytes were identified by expression of the transcriptional regulator peroxisome proliferator-activated receptor $\gamma$ (Figure 4E). Serial tissue sections were coimmunostained with UCP1 and peroxisome proliferator-activated receptor $\gamma$ coactivator $1 \alpha$, which interacts with peroxisome proliferator-activated receptor $\gamma$ and is preferentially expressed in brown/beige adipocytes as compared to white adipocytes, ${ }^{30}$ and we observed colocalization of these factors (Figure 4, A-D). In contrast, $\mathrm{UCP}^{+}$cells were negative for expression of PRDM16 (Figure 4F) and the beige fat markers CD137 (Figure 4G), T-Box 1 (Figure 4H), and Homeobox C9 (data not shown). ${ }^{21}$

\section{UCP1 ${ }^{+}$Cells within Cartilage and Nerves in HO Tissues}

Immunohistochemical staining for UCP1 also revealed cells positive for this protein within unique regions of the tissue samples of $\mathrm{HO}$, including areas of cartilage and nerves. UCP1 expression (Figure 5B) was observed within cartilage, which was identified by staining with the cartilage marker aggrecan $^{31}$ (Figure 5C) and the precartilage marker Sry-Box $9^{32}$ (Figure 5D). Cells positive for UCP1 (Figure 5G) were also found in peripheral nerves within the $\mathrm{HO}$ tissues, as demonstrated by neurofilament staining (Figure 5H). Hematoxylin and eosin staining (Figure 5, A and F) and merged views (Figure 5, E and I) were also used. UCP1 expression was not detected in these regions within control tissues that were not undergoing $\mathrm{HO}$ (data not shown).

\section{Expression of ADRB3 in HO Tissue}

The expression of ADRB 3 was assessed in HO tissue along with UCP1 (Figure 6). We observed various patterns of

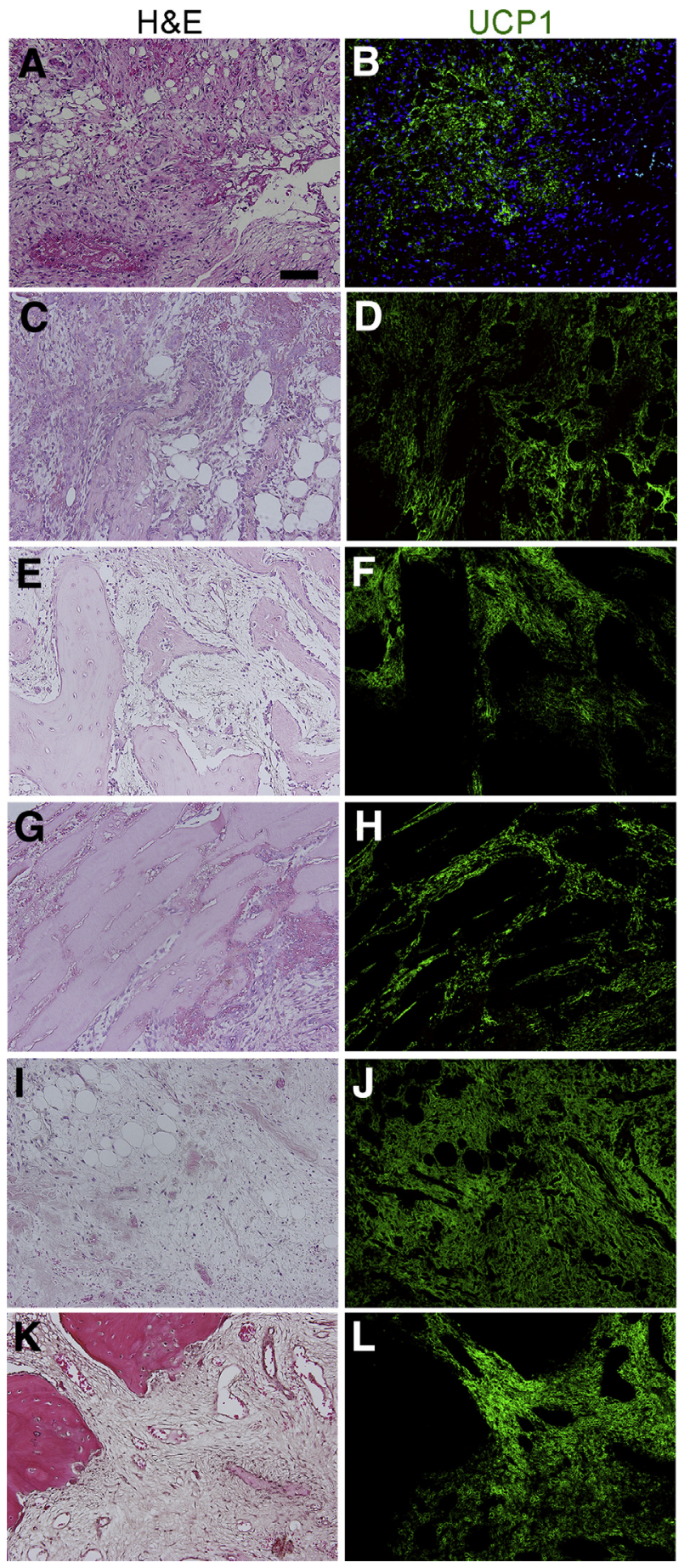

Figure 2 Analysis of UCP1 expression within $\mathrm{H} 0$ tissue samples. A, C, E, G, I, and K: Corresponding serial sections stained with hematoxylin and eosin (H\&E). B, D, F, H, J, and L: Representative photomicrographs of H0 tissues immunostained with UCP1 (green). DAPI (blue) was used as a counterstain to identify cell nuclei (B). These regions of $\mathrm{UCP} 1^{+}$fat are found interspersed with bone (C and $\mathbf{E})$, muscle $(\mathbf{G})$, and vessels (K). Scale bar $=100 \mu \mathrm{m}(\mathbf{A}-\mathbf{L})$.

staining. In the first pattern, staining was mostly in the nerve, with UCP1 staining primarily in the perineurium and staining for ADRB3 in the endoneurium (Figure 6A). The second pattern showed staining for both ADRB3 and UCP1 


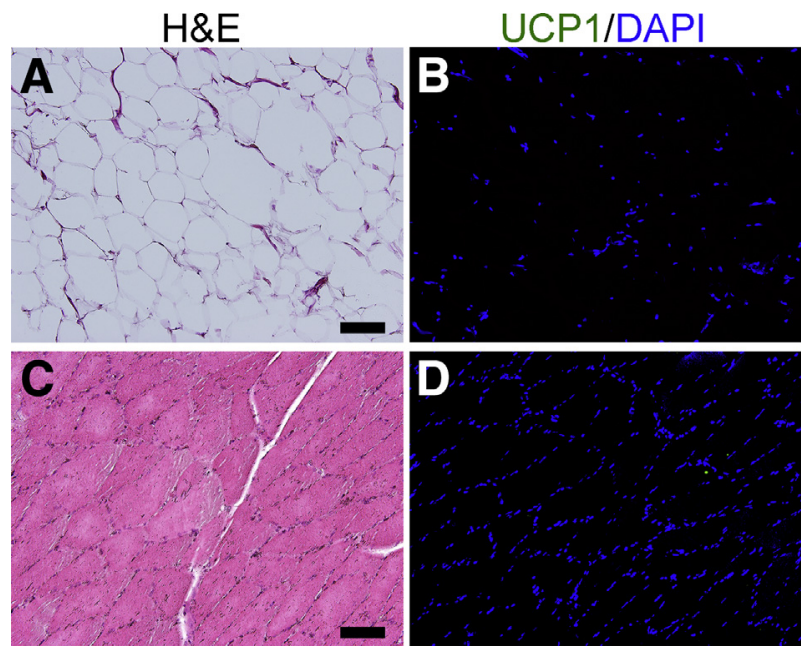

Figure 3 Analysis of UCP1 expression within control tissue samples. Representative photomicrographs of control tissues from extremity-injured patients who did not develop evidence of HO. A and C: The corresponding serial sections stained with hematoxylin and eosin (H\&E) are shown. B and D: Samples were immunostained with UCP1 and found to be negative for UCP1 staining. Tissues were counterstained with DAPI (blue) to identify cell nuclei. Representative regions of fat and muscle within the samples, areas found to be positive in the HO tissues, are highlighted here. Scale bars $=100 \mu \mathrm{m}(\mathbf{A}-\mathbf{D})$.

within regions of adipose tissue and vessels (Figure 6B). The third pattern showed staining for both ADRB3 and UCP1 in cells lining the surface of bone (Figure 6C).

\section{Radiographic Analysis of Heterotopic Ossification}

Extremity wounds from blast-related combat injuries are typically extremely large and complex because the patients undergo multiple rounds of surgical debridements ( 2 to 14 total) to remove nonviable tissue and biofilm. Also, revisions (limb salvage) are conducted before definitive wound closure at 7 to 21 days after injury. The samples analyzed herein termed early $\mathrm{HO}$ were taken from patients with no radiographic evidence of HO. However, X-rays and computed tomographic scans were taken routinely during postoperative care to evaluate the wound healing and to monitor for $\mathrm{HO}$ development. The images shown in Figure 7 illustrate the radiographic $\mathrm{HO}$ development that occurs 4 to 20 weeks after injury in these transfemoral amputees. No ectopic bone was observed by X-ray before 14 days. At 4 weeks, patients developed wispy evidence of tissue mineralization that progressed to form isolated islands of bone in the soft tissues and exostoses that extend from the distal end of the residual femur into the soft tissue. The HO continued to mature over 6 to 20 weeks. Representative $\mathrm{X}$-ray analyses of two patients at 4 (Figure 7A) and 20 (Figure 7B) weeks after injury are shown in Figure 7.

\section{Discussion}

The brown fat that appears in human HO lesions can be characterized by comparison with known phenotypes of brown adipose tissue found naturally in the human body. Most of the adipose tissue observed in our study expressed UCP1, confirming that it is similar to classic brown fat in this important aspect and indicating that the tissue is capable of thermogenesis through uncoupled aerobic respiration. Furthermore, the data indicate that the $\mathrm{UCP}^{+}$cells observed most closely resembled brown fat as opposed to
H\&E

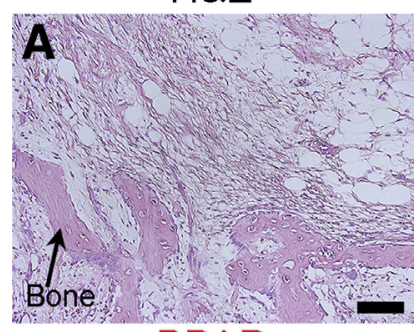

PPARY

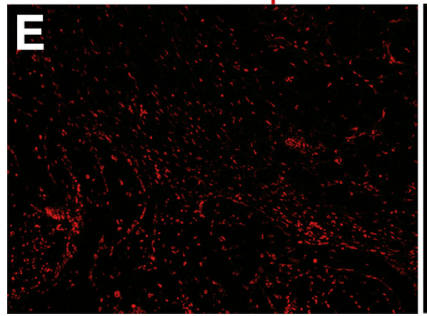

UCP1

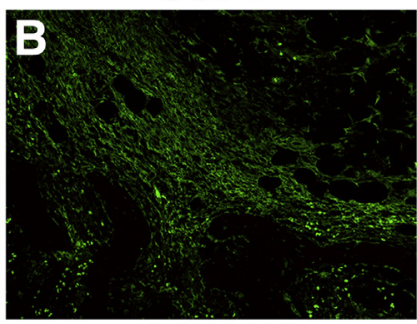

PRDM16

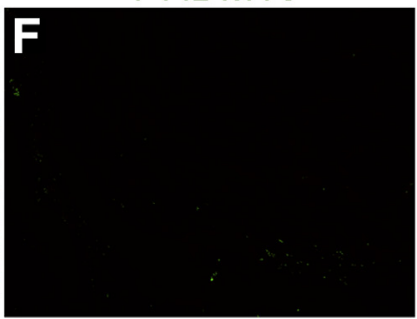

PGC1a

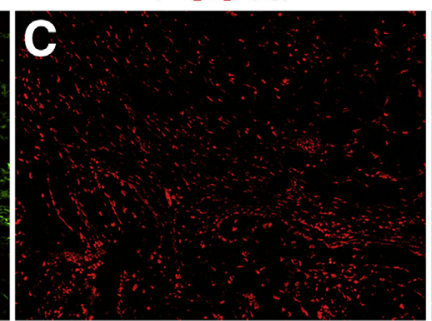

CD137

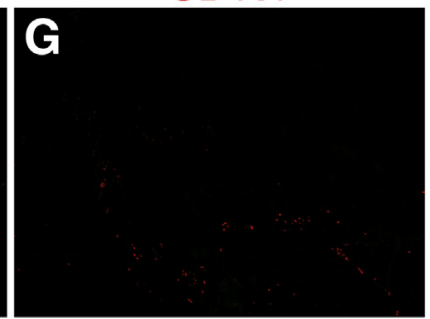

Merge

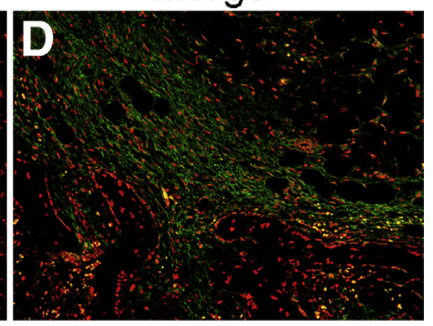

TBX1

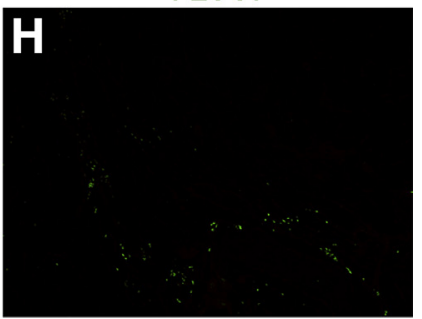

Figure 4 Characterization of $\mathrm{UCP} 1^{+}$adipocytes within $\mathrm{HO}$ tissues. A: Image of the same region stained with hematoxylin and eosin (H\&E) on a tissue section adjacent to the sections used for immunostaining. B and C: Representative images of UCP1 expression in the H0 tissues shows UCP1 ${ }^{+}$cells (green; B) coexpressing peroxisome proliferator-activated receptor $\gamma$ coactivator $1 \alpha$ (PGC1 $\alpha$; red; C). D: A merged image of B and C. E: Peroxisome proliferator-activated receptor $\gamma($ PPAR $\gamma$ ) expression (red) is observed colocalizing with these UCP1-expressing cells. F-H: Additional immunostaining of serial sections reveals that these cells do not express the transcriptional regulator PRDM16 (F), or typical markers of beige fat, including CD137 (G) and T-Box 1 (TBX1) (H). A small amount of autofluorescence from red blood cells was noted within these sections. Scale bar $=100 \mu \mathrm{m}(\mathbf{A}-\mathbf{H})$. 

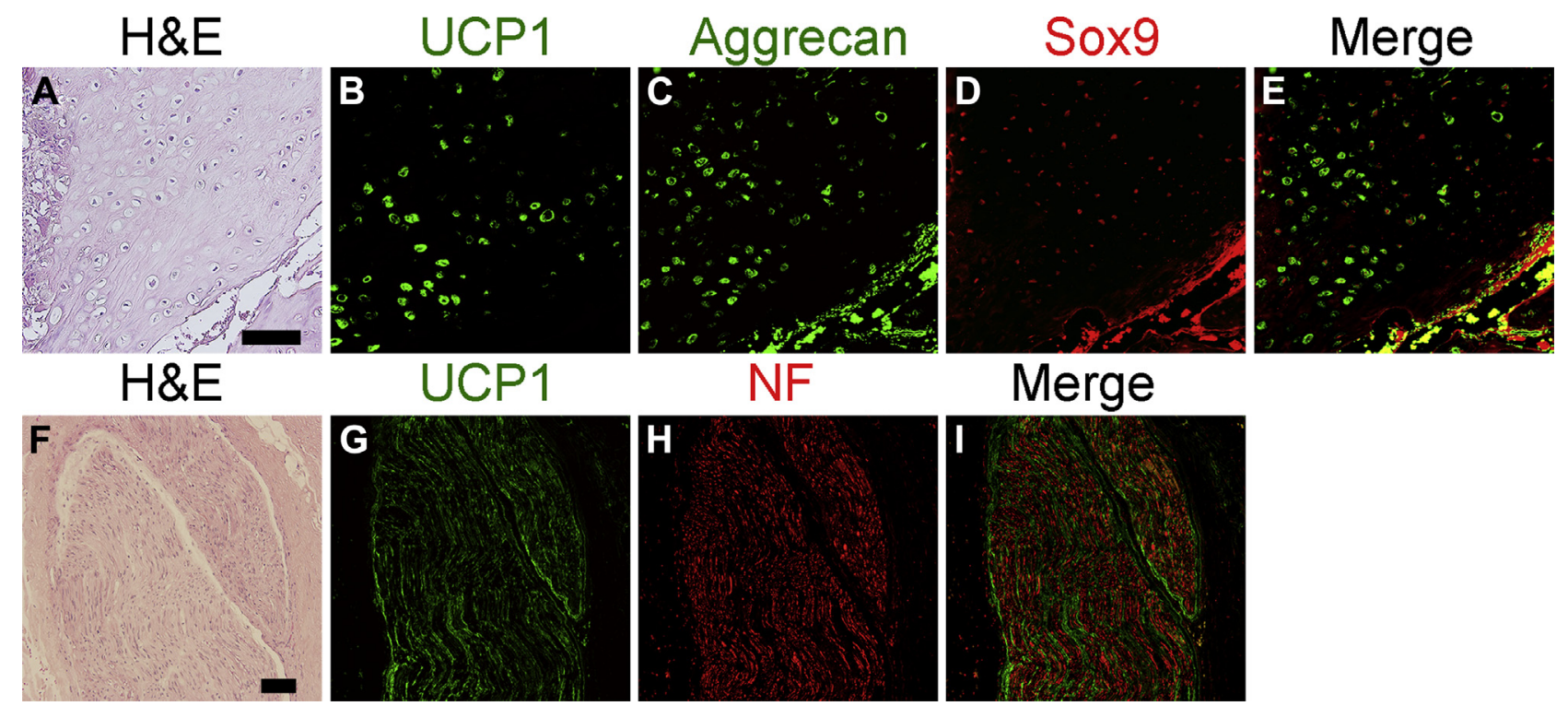

Figure 5 Cartilage and nerves contain cells positive for UCP1. Representative images of areas of cartilage and nerve within the H0 tissue found to express UCP1. A and F: Adjacent hematoxylin and eosin (H\&E)-stained sections from the same tissue are shown. B and G: Tissues were serially sectioned, immunostained with an antibody to UCP1 (green), and analyzed. C and D: Cartilage tissue was identified by coimmunostaining of a serial section with antibodies to both aggrecan (green; C) and the nuclear transcription factor Sry-Box 9 (Sox9; red; D). A subset of the aggrecan-positive cells coexpressed Sox9, which is an earlier marker of cartilage formation and indicative of chondrogenesis. E: A merged image of $\mathbf{C}$ and $\mathbf{D}$. H: Nerves were identified by the neural marker neurofilament (NF; red). I: A merged image of $\mathbf{G}$ and $\mathbf{H}$. Scale bars $=100 \mu \mathrm{m}(\mathbf{A}-\mathbf{I})$.

beige fat, as they were negative for CD137, T-Box 1, and Homeobox C9, all markers for the beige/brite fat subtype. ${ }^{23}$ However, the data demonstrate a lack of expression of PRDM16, indicating that these cells have an origin different from the brown fat they resemble. Brown fat contained in depots arises from precursors that express Myf5, ${ }^{13}$ and its biogenesis requires the expression of PRDM16, a transcription factor essential for the differentiation of precursors into brown fat instead of muscle. ${ }^{13}$ In our previous studies using our mouse model, induction of $\mathrm{HO}$ caused the biogenesis of similar brown adipocyte-like cells, but these cells also did not express PRDM16. ${ }^{11}$ In the mouse model, perineurial cells expressing ADRB3 that lined peripheral nerves not only migrated toward the site of $\mathrm{HO}$ but also expressed angiogenic factors. ${ }^{10,11}$ On activation of ADRB3, mitochondrial synthesis in these cells increased and their expression of UCP1 increased 70-fold, leading to their brown adipocyte-like appearance. ${ }^{9,11} \mathrm{We}$, therefore, suspect that these cells phenotypically resemble brown more closely than beige fat, yet bear unique characteristics and origin.

It is also noteworthy that cells expressing UCP1 described herein seem to be present both in sections where there is little or no bone present, as well as in sections containing either immature or mature bone. Surprisingly, the $\mathrm{UCP} 1^{+}$cells also appear to surround the bone in many instances. Although the reasons for this are unclear, we have found that tBAT in the mouse model contains osteocalcin (A.R.D. and E.A.O.-D., unpublished data) as well as citrate. ${ }^{33}$ Because osteocalcin is the most abundant noncollagenous component of the bone matrix, whereas citrate comprises between $1 \%$ and $2 \%$ by weight of the matrix, ${ }^{34}$ it is conceivable that these cells deliver at least a portion of these components to the matrix.

Blast and burn injuries lead to high incidences of $\mathrm{HO}$ in humans. ${ }^{8}$ Previous studies have shown that metabolic changes accompany HO. ${ }^{9,33}$ Some of these changes likely result from the appearance of brown fat in the lesion and subsequent uncoupled aerobic respiration and altered triglyceride homeostasis. ${ }^{35}$ Studies evaluating brown fat activation after burn injury indicate it contributes to the metabolic changes observed after burns. ${ }^{36,37}$ The induction of brown fat-mediated changes in metabolism may have a connection to $\mathrm{HO}$ pathology because of burn injury. Surprisingly, in all cases, the appearance of these brown fat cells in white fat have been linked to the $\beta 3$-adrenergic receptor. ${ }^{23,24}$

The $\mathrm{UCP} 1^{+}$adipocytes seen in the human HO tissue samples in this study display a similar phenotype to the transient brown adipocytes previously identified using our mouse model of HO. ${ }^{11,38}$ The brown adipose-like tissue that predates ossification in both models likely has a similar role. We suspect the brown adipocyte-like cells in the human lesions function to generate a microenvironment conducive for chondrogenesis and bone formation, as we have seen in our mouse studies. The ability of tBAT to perform uncoupled aerobic respiration provides an effective means of generating a hypoxic local environment. The reduced oxygen tension stimulates angiogenesis, an essential step in the formation of bone. ${ }^{9,10}$ Furthermore, recent studies in tissues at risk for $\mathrm{HO}$ have shown that the enhancement of microcirculation, which consequently prevents local tissue hypoxia, significantly reduced the occurrence of $\mathrm{HO}^{39}$ These findings suggest that the brown 

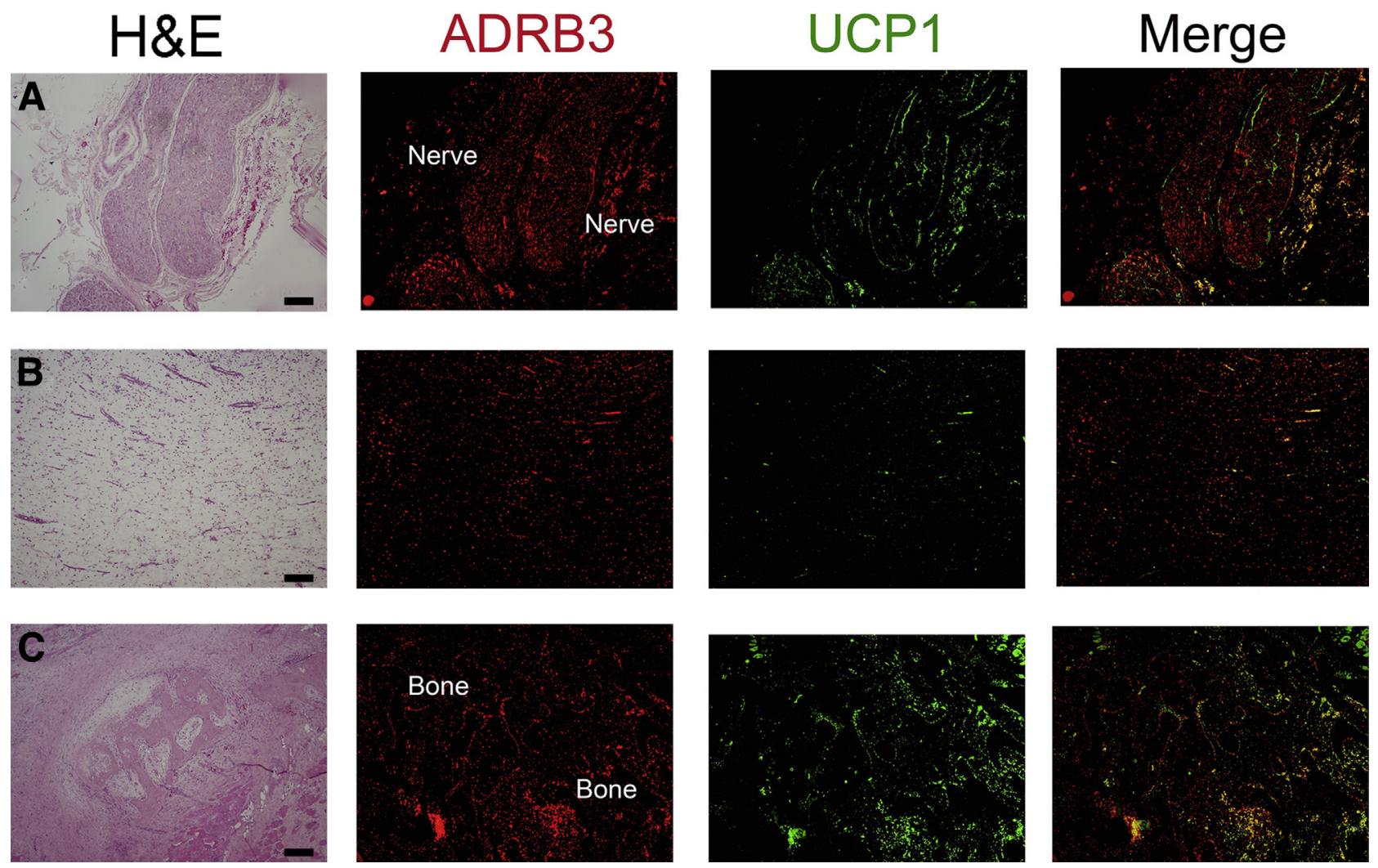

Figure 6 Costaining of ADRB3 and UCP1 in human H0 tissue. Three tissue samples of human H0 were stained with ADRB3 (red) and UCP1 (green). Adjacent hematoxylin and eosin (H\&E)-stained sections from the same tissue are shown. Scale bar $=200 \mu \mathrm{m}(\mathbf{A}-\mathbf{C})$.

adipocyte-like cells may contribute to providing a permissive environment for HO. The tBAT also secretes vascular endothelial growth factors $\mathrm{A}$ and $\mathrm{D} .{ }^{10}$ This causes neovascularization at the site of bone formation, enabling osteoprogenitors from the nerve to flow to and then extravasate across the vessel wall into the site of new bone formation. ${ }^{29}$

We observed UCP1 ${ }^{+}$cells in nerves and cartilage in the tissue samples of human HO. Our previous study of bone morphogenetic protein 2-induced HO shows that these brown adipocyte-like cells in mice come from peripheral nerve progenitor cells. ${ }^{11}$ The presence of $\mathrm{UCP}^{+}{ }^{+}$cells in peripheral nerves observed in the human $\mathrm{HO}$ lesions further supports those findings. The presence of $\mathrm{UCP}^{+}$cells in cartilage may reflect a common origin of transient brown fat and chondrocytes. Using lineage tracing, we recently reported a multipotential, $\mathrm{Wnt}^{+}$neural progenitor that produces both prechondrocytes and transient brown fat during $\mathrm{HO}$ in the mouse. ${ }^{26}$

We observed three staining patterns for ADRB3 and UCP1 in HO tissues. In the pattern observed only in nerves, UCP1 was expressed primarily in cells in the perineurium, whereas ADRB3 was expressed mostly in the endoneurium. Although there was a large and significant increase in expression of ADRB3 in both the endoneurium and perineurium in the mouse model after bone morphogenetic protein 2 induction, at no time was this receptor expressed mostly in the endoneurium. Therefore, in human HO, there was minimal overlap of the expression of ADRB3 and UCP1 in the nerve, whereas there was considerable overlap in the mouse model. ${ }^{11}$ Although we do not understand the reason for this difference, there is considerable variation between the anatomy of mouse and human nerves in that human nerves have multiple fascicles as well as a much more substantial epineurium and perineurium. Outside of
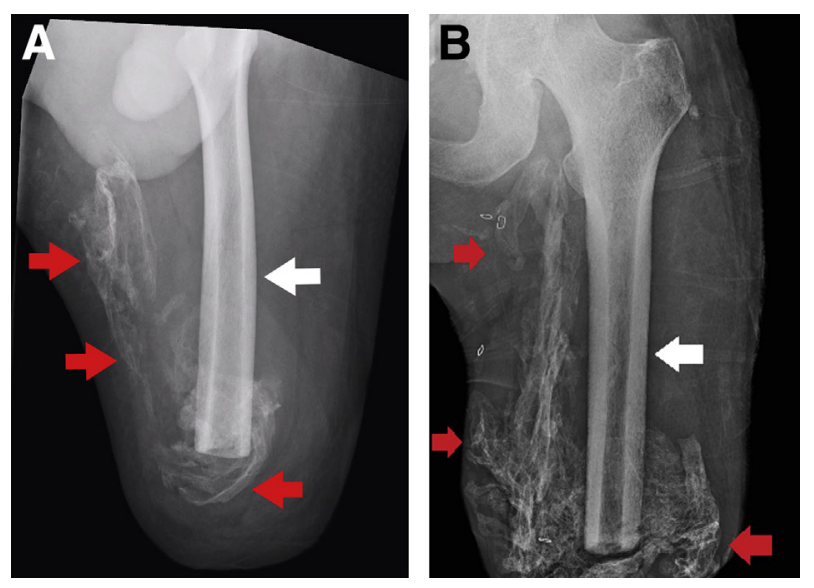

Figure 7 Radiographic analysis of HO. X-rays of patients with a transfemoral amputation at 1 (A) and 5 (B) months after combat injury. White arrows indicate residual femur; red arrows, radiographically evident heterotopic bone in the soft tissue. 
the nerve, there is considerable, but not complete, overlap of ADRB3 and UCP1.

In several of the HO tissue samples, we noted the presence of nerves embedded within the region of newly forming bone. The traumatic insult that induces $\mathrm{HO}$ in these tissues likely results in injury to the peripheral nerves as well, which may activate neural progenitors. As the neural tissue is spared during surgery, we did not detect nerves in all of the samples. However, in certain sections, there were many nerves observed where few were expected.

In this study, we translated our previous findings from our mouse model of $\mathrm{HO}$ to the human disease. We detected brown adipose-like tissue in human HO induced by traumatic injury with features similar to those of brown fat in the mouse model. Understanding the key cellular players contributing to $\mathrm{HO}$ and the specific mechanisms related to this aberrant process can help identify new targets to prevent or treat this condition.

\section{References}

1. Sullivan MP, Torres SJ, Mehta S, Ahn J: Heterotopic ossification after central nervous system trauma: a current review. Bone Joint Res 2013, 2:51-57

2. Levi B, Jayakumar P, Giladi A, Jupiter JB, Ring DC, Kowalske K, Gibran NS, Herndon D, Schneider JC, Ryan CM: Risk factors for the development of heterotopic ossification in seriously burned adults: a National Institute on Disability, Independent Living and Rehabilitation Research burn model system database analysis. J Trauma Acute Care Surg 2015, 79:870-876

3. Salisbury E, Sonnet C, Heggeness M, Davis AR, Olmsted-Davis E: Heterotopic ossification has some nerve. Crit Rev Eukaryot Gene Expr 2010, 20:313-324

4. Alfieri KA, Forsberg JA, Potter BK: Blast injuries and heterotopic ossification. Bone Joint Res 2012, 1:192-197

5. Alfieri KA, Potter BK, Davis TA, Wagner MB, Elster EA, Forsberg JA: Preventing heterotopic ossification in combat casualties: which models are best suited for clinical use? Clin Orthop Relat Res 2015, 473:2807-2813

6. Forsberg JA, Pepek JM, Wagner S, Wilson K, Flint J, Andersen RC, Tadaki D, Gage FA, Stojadinovic A, Elster EA: Heterotopic ossification in high-energy wartime extremity injuries: prevalence and risk factors. J Bone Joint Surg Am 2009, 91:1084-1091

7. Polfer EM, Forsberg JA, Fleming ME, Potter BK: Neurovascular entrapment due to combat-related heterotopic ossification in the lower extremity. J Bone Joint Surg Am 2013, 95:e195, (191-196)

8. Potter BK, Forsberg JA, Davis TA, Evans KN, Hawksworth JS, Tadaki D, Brown TS, Crane NJ, Burns TC, O'Brien FP, Elster EA: Heterotopic ossification following combat-related trauma. J Bone Joint Surg Am 2010, 92 Suppl 2:74-89

9. Olmsted-Davis E, Gannon FH, Ozen M, Ittmann MM, Gugala Z, Hipp JA, Moran KM, Fouletier-Dilling CM, Schumara-Martin S, Lindsey RW, Heggeness MH, Brenner MK, Davis AR: Hypoxic adipocytes pattern early heterotopic bone formation. Am J Pathol 2007, 170:620-632

10. Dilling CF, Wada AM, Lazard ZW, Salisbury EA, Gannon FH, Vadakkan TJ, Gao L, Hirschi K, Dickinson ME, Davis AR, OlmstedDavis EA: Vessel formation is induced prior to the appearance of cartilage in BMP-2-mediated heterotopic ossification. J Bone Miner Res 2010, 25:1147-1156

11. Salisbury EA, Lazard ZW, Ubogu EE, Davis AR, Olmsted-Davis EA: Transient brown adipocyte-like cells derive from peripheral nerve progenitors in response to bone morphogenetic protein 2. Stem Cells Transl Med 2012, 1:874-885

12. Oelkrug R, Goetze N, Exner C, Lee Y, Ganjam GK, Kutschke M, Muller S, Stohr S, Tschop MH, Crichton PG, Heldmaier G, Jastroch M, Meyer CW: Brown fat in a protoendothermic mammal fuels eutherian evolution. Nat Commun 2013, 4:2140

13. Seale P, Bjork B, Yang W, Kajimura S, Chin S, Kuang S, Scime A, Devarakonda S, Conroe HM, Erdjument-Bromage H, Tempst P, Rudnicki MA, Beier DR, Spiegelman BM: PRDM16 controls a brown fat/skeletal muscle switch. Nature 2008, 454: 961-967

14. Nedergaard J, Bengtsson T, Cannon B: Unexpected evidence for active brown adipose tissue in adult humans. Am J Physiol Endocrinol Metab 2007, 293:E444-E452

15. Virtanen KA, Lidell ME, Orava J, Heglind M, Westergren R, Niemi T, Taittonen M, Laine J, Savisto NJ, Enerback S, Nuutila P: Functional brown adipose tissue in healthy adults. N Engl J Med 2009, 360 $1518-1525$

16. Cypess AM, Lehman S, Williams G, Tal I, Rodman D, Goldfine AB, Kuo FC, Palmer EL, Tseng YH, Doria A, Kolodny GM, Kahn CR Identification and importance of brown adipose tissue in adult humans. N Engl J Med 2009, 360:1509-1517

17. Saito M, Okamatsu-Ogura Y, Matsushita M, Watanabe K, Yoneshiro T, Nio-Kobayashi J, Iwanaga T, Miyagawa M, Kameya T, Nakada K, Kawai Y, Tsujisaki M: High incidence of metabolically active brown adipose tissue in healthy adult humans: effects of cold exposure and adiposity. Diabetes 2009, 58:1526-1531

18. van Marken Lichtenbelt WD, Vanhommerig JW, Smulders NM Drossaerts JM, Kemerink GJ, Bouvy ND, Schrauwen P, Teule GJ: Cold-activated brown adipose tissue in healthy men. N Engl J Med 2009, 360:1500-1508

19. Cypess AM, White AP, Vernochet C, Schulz TJ, Xue R, Sass CA, Huang TL, Roberts-Toler C, Weiner LS, Sze C, Chacko AT, Deschamps LN, Herder LM, Truchan N, Glasgow AL, Holman AR, Gavrila A, Hasselgren PO, Mori MA, Molla M, Tseng YH: Anatomical localization, gene expression profiling and functional characterization of adult human neck brown fat. Nat Med 2013, 19:635-639

20. Nagano G, Ohno H, Oki K, Kobuke K, Shiwa T, Yoneda M, Kohno N Activation of classical brown adipocytes in the adult human perirenal depot is highly correlated with PRDM16-EHMT1 complex expression. PLoS One 2015, 10:e122584

21. Harms M, Seale P: Brown and beige fat: development, function and therapeutic potential. Nat Med 2013, 19:1252-1263

22. Petrovic N, Walden TB, Shabalina IG, Timmons JA, Cannon B, Nedergaard J: Chronic peroxisome proliferator-activated receptor gamma (PPARgamma) activation of epididymally derived white adipocyte cultures reveals a population of thermogenically competent, UCP1-containing adipocytes molecularly distinct from classic brown adipocytes. J Biol Chem 2010, 285:7153-7164

23. Sidossis L, Kajimura S: Brown and beige fat in humans: thermogenic adipocytes that control energy and glucose homeostasis. J Clin Invest 2015, 125:478-486

24. Sidossis LS, Porter C, Saraf MK, Borsheim E, Radhakrishnan RS, Chao T, Ali A, Chondronikola M, Mlcak R, Finnerty CC, Hawkins HK, Toliver-Kinsky T, Herndon DN: Browning of subcutaneous white adipose tissue in humans after severe adrenergic stress. Cell Metab 2015, 22:219-227

25. Motyl KJ, Bishop KA, DeMambro VE, Bornstein SA, Le P, Kawai M, Lotinun S, Horowitz MC, Baron R, Bouxsein ML, Rosen CJ: Altered thermogenesis and impaired bone remodeling in Misty mice. J Bone Miner Res 2013, 28:1885-1897

26. Olmsted-Davis EA, Salisbury EA, Hoang D, Davis EL, Lazard Z, Sonnet C, Davis TA, Forsberg JA, Davis AR: Progenitors in peripheral nerves launch heterotopic ossification. Stem Cells Transl Med 2017, 6: 1109-1119

27. Davis TA, O'Brien FP, Anam K, Grijalva S, Potter BK, Elster EA: Heterotopic ossification in complex orthopaedic combat wounds: 
quantification and characterization of osteogenic precursor cell activity in traumatized muscle. J Bone Joint Surg Am 2011, 93: $1122-1131$

28. Kaplan FS, Glaser DL, Hebela N, Shore EM: Heterotopic ossification. J Am Acad Orthop Surg 2004, 12:116-125

29. Lazard ZW, Olmsted-Davis EA, Salisbury EA, Gugala Z, Sonnet C, Davis EL, Beal E 2nd, Ubogu EE, Davis AR: Osteoblasts have a neural origin in heterotopic ossification. Clin Orthop Relat Res 2015, 473:2790-2806

30. Puigserver P, Spiegelman BM: Peroxisome proliferator-activated receptor-gamma coactivator 1 alpha (PGC-1 alpha): transcriptional coactivator and metabolic regulator. Endocr Rev 2003, 24:78-90

31. Doege KJ, Sasaki M, Kimura T, Yamada Y: Complete coding sequence and deduced primary structure of the human cartilage large aggregating proteoglycan, aggrecan: human-specific repeats, and additional alternatively spliced forms. J Biol Chem 1991, 266: 894-902

32. Murakami S, Kan M, McKeehan WL, de Crombrugghe B: Up-regulation of the chondrogenic Sox 9 gene by fibroblast growth factors is mediated by the mitogen-activated protein kinase pathway. Proc Natl Acad Sci U S A 2000, 97:1113-1118

33. Davis EL, Salisbury EA, Olmsted-Davis E, Davis AR: Anaplerotic accumulation of tricarboxylic acid cycle intermediates as well as changes in other key metabolites during heterotopic ossification. J Cell Biochem 2016, 117:1044-1053
34. Costello LC, Chellaiah M, Zou J, Franklin RB, Reynolds MA: The status of citrate in the hydroxyapatite/collagen complex of bone; and its role in bone formation. J Regen Med Tissue Eng 2014, 3:4

35. Bartelt A, Bruns OT, Reimer R, Hohenberg H, Ittrich H, Peldschus K, Kaul MG, Tromsdorf UI, Weller H, Waurisch C, Eychmuller A, Gordts PL, Rinninger F, Bruegelmann K, Freund B, Nielsen P, Merkel M, Heeren J: Brown adipose tissue activity controls triglyceride clearance. Nat Med 2011, 17:200-205

36. Yo K, Yu YM, Zhao G, Bonab AA, Aikawa N, Tompkins RG, Fischman AJ: Brown adipose tissue and its modulation by a mitochondria-targeted peptide in rat burn injury-induced hypermetabolism. Am J Physiol Endocrinol Metab 2013, 304:E331-E341

37. Carter EA, Bonab AA, Hamrahi V, Pitman J, Winter D, Macintosh LJ, Cyr EM, Paul K, Yerxa J, Jung W, Tompkins RG, Fischman AJ: Effects of burn injury, cold stress and cutaneous wound injury on the morphology and energy metabolism of murine brown adipose tissue (BAT) in vivo. Life Sci 2011, 89:78-85

38. Olmsted-Davis EA, Gugala Z, Gannon FH, Yotnda P, McAlhany RE, Lindsey RW, Davis AR: Use of a chimeric adenovirus vector enhances BMP2 production and bone formation. Hum Gene Ther 2002, 13: $1337-1347$

39. Zimmermann SM, Schwitter LW, Scheyerer MJ, Jentzsch T, Simmen HP, Werner CM: Prevention of heterotopic ossification: an experimental study using a plasma expander in a murine model. BMC Surg 2016, 16:29 